\title{
Systemic Monocyte Chemotactic Protein-1 Inhibition Modifies Renal Macrophages and Restores Glomerular Endothelial Glycocalyx and Barrier Function in Diabetic Nephropathy
}

\author{
Margien G.S. Boels, ${ }^{*}$ Angela Koudijs, ${ }^{*}$ M. Cristina Avramut, ${ }^{\dagger}$ Wendy M.P.J. Sol, ${ }^{*}$ Gangqi Wang, ${ }^{*}$ \\ Annemarie M. van Oeveren-Rietdijk, ${ }^{*}$ Anton Jan van Zonneveld, ${ }^{*}$ Hetty C. de Boer, ${ }^{*}$ Johan van der Vlag, ${ }^{\ddagger}$ Cees van Kooten, ${ }^{*}$ \\ Dirk Eulberg, ${ }^{\S}$ Bernard M. van den Berg, ${ }^{*}$ Daphne H.T. IJpelaar, ${ }^{*}$ and Ton J. Rabelink*
}

From the Einthoven Laboratory for Vascular and Regenerative Medicine, * Department of Internal Medicine, Division of Nephrology, and the Department of Molecular Cell Biology, ${ }^{\dagger}$ Leiden University Medical Center, Leiden, the Netherlands; the Department of Nephrology, ${ }^{\ddagger}$ Radboud Institute for Molecular Life Sciences, Radboud University Medical Center, Nijmegen, the Netherlands; and NOXXON Pharma AG, ${ }^{\S}$ Berlin, Germany

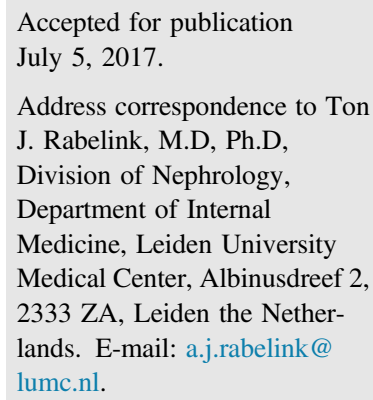

\begin{abstract}
Inhibition of monocyte chemotactic protein-1 (MCP-1) with the Spiegelmer emapticap pegol (NOX-E36) shows long-lasting albuminuria-reducing effects in diabetic nephropathy. MCP-1 regulates inflammatory cell recruitment and differentiation of macrophages. Because the endothelial glycocalyx is also reduced in diabetic nephropathy, we hypothesized that MCP-1 inhibition restores glomerular barrier function through influencing macrophage cathepsin L secretion, thus reducing activation of the glycocalyxdegrading enzyme heparanase. Four weeks of treatment of diabetic Apoe knockout mice with the mouse-specific NOX-E36 attenuated albuminuria without any change in systemic hemodynamics, despite persistent loss of podocyte function. MCP-1 inhibition, however, increased glomerular endothelial glycocalyx coverage, with preservation of heparan sulfate. Mechanistically, both glomerular cathepsin $\mathrm{L}$ and heparanase expression were reduced. MCP-1 inhibition resulted in reduced CCR2expressing Ly6Chi monocytes in the peripheral blood, without affecting overall number of kidney macrophages at the tissue level. However, the $\mathrm{CD}_{206^{+}} / \mathrm{Mac}^{+}$cell ratio, as an index of presence of antiinflammatory macrophages, increased in diabetic mice after treatment. Functional analysis of isolated renal macrophages showed increased release of IL-10, whereas tumor necrosis factor and cathepsin $\mathrm{L}$ release was reduced, further confirming polarization of tissue macrophages toward an antiinflammatory phenotype during mouse-specific NOX-E36 treatment. We show that MCP-1 inhibition restores glomerular endothelial glycocalyx and barrier function and reduces tissue inflammation in the presence of ongoing diabetic injury, suggesting a therapeutic potential for NOX-E36 in diabetic nephropathy. (Am J Pathol 2017, 187: 2430-2440; http://dx.doi.org/10.1016/j.ajpath.2017.07.020)
\end{abstract}

Diabetic nephropathy is the major cause of end-stage renal disease. Although optimal blood pressure treatment using drugs that interfere with the renin-angiotensin system has been shown to slow progression of diabetic nephropathy, many patients still progress to end-stage renal disease. ${ }^{1}$ In recent years, new strategies to slow the progression of chronic kidney disease in patients with diabetic nephropathy focused on inhibition of inflammation. ${ }^{2}$ One such strategy constitutes inhibition of monocyte chemotactic protein-1
(MCP-1) to prevent binding to its cognate receptor CCR2. MCP-1 is considered to be involved in recruitment of monocytes and migration of monocytes and macrophages. $^{3-6}$ In patients with diabetic nephropathy, the

Supported by the Dutch Kidney Foundation Kolff grant 14OKG06 (D.H.T.IJ.) and Glycoren consortium grant CP09.03 (T.J.R.).

Disclosures: D.E. is employed at NOXXON Pharma AG.

Presented in part as an abstract at the American Society of Nephrology Kidney Week, November 15 to 20, 2016, Chicago, IL. 
increased presence of MCP-1 in renal tissue and elevated levels in urine suggest that macrophages play a pathogenic role in the development of proteinuria, glomerular damage, and the progression of renal disease in humans. ${ }^{7}$ Indeed, Nguyen et $\mathrm{al}^{8}$ showed that macrophages are already present in glomeruli in early diabetic nephropathy, whereas the number of interstitial macrophages correlates with progression of renal insufficiency. Recently, we demonstrated similar findings in a large autopsy study showing that glomerular macrophages were already present in biopsy specimens with mild diabetic nephropathy, suggesting a role for macrophages in proteinuria and early diabetes-induced damage. ${ }^{9}$

In experimental models of streptozotocin-induced diabetic nephropathy, macrophage recruitment to the glomeruli could be prevented by genetic deletion of MCP-1. ${ }^{10}$ Similarly, pharmacological blockade of MCP-1 prevented glomerular macrophage recruitment and attenuated albuminuria in uninephrectomized $d b / d b$ mice. ${ }^{11,12}$ In addition, observations on alleviation of acute rejection through MCP-1 blockade point toward the potential of the MCP-1/ CCR2 pathway to modulate inflammation. Clinically, the MCP-1/CCR2 axis has been targeted by receptor-specific antibodies and small molecules. For example, blockade of CCR2 with the small molecule CCX140-B in patients with diabetic nephropathy reduced albuminuria. ${ }^{13}$ Recently, inhibition of MCP-1 with emapticap pegol (NOX-E36), a structured L-enantiomeric RNA (so-called Spiegelmer), decreased albuminuria in patients with diabetic nephropathy. ${ }^{14}$ The mechanism of the reduction in albuminuria by MCP-1 inhibition, however, is still not understood.

The glomerular barrier for albumin filtration is an interplay between endothelial cells, podocytes, and the glomerular basement membrane. Fenestrated glomerular endothelial cells are covered with the glycocalyx, a gel-like polyanionic carbohydrate layer with embedded proteins. ${ }^{15,16}$ Increased activity of glycocalyx-degrading enzymes, such as heparanase and hyaluronidase, has long been recognized in diabetic nephropathy. ${ }^{17}$ The activity of heparanase, which is secreted as an inactive precursor by endothelial cells and podocytes, is increased dramatically after subsequent activation by the enzyme cathepsin L. ${ }^{18}$ Cathepsin $\mathrm{L}$ can also be secreted into the extracellular space by infiltrated glomerular macrophages, making these cells candidates for renal heparanase activation and loss of glycocalyx. This mechanism of action of MCP-1 inhibition was evaluated in this study in diabetic Apoe knockout (KO) mice and further validated in fluorescence-activated cell sorting (FACS) isolated macrophages of the renal tissue of these mice.

\section{Materials and Methods}

\section{Animal Studies}

Six-week-old male Apoe KO C57BL/6J mice (Jackson Laboratory, Bar Harbor, ME) were rendered diabetic, as described before. ${ }^{15}$ In short, $60 \mathrm{mg} / \mathrm{kg}$ streptozotocin (Sigma-Aldrich, St. Louis, MO) in citrate buffer was injected i.p. for 5 consecutive days; control Apoe KO mice received citrate buffer alone. Twelve weeks after induction of diabetes, mice were treated with s.c. injections of $20 \mathrm{mg} / \mathrm{kg}$ mouse-specific NOX-E36 (mNOX-E36) or inactive control Spiegelmer (revmNOX-E36) in 5\% glucose three times a week for 4 weeks. This dose is based on previous studies with mNOX-E36 in C57BL/6J mice ${ }^{19}$; $n=23$ per group were followed up until the end of treatment, and $n=10$ per group were followed up until 4 weeks after treatment ( $n=11$ for control). (rev)mNOX-E36 concentrations were determined 1 to 6 hours after injections in lithium heparin plasma. All diabetic animals had free access to cholesterol-enriched $(0.15 \%)$ chow (TechnilabBMI, Someren, the Netherlands), and control Apoe KO mice were fed with standard chow for baseline measurements $(n=13)$. Animal experiments were approved by the ethical committee on animal care and experimentation of the Leiden University Medical Center (Leiden, the Netherlands). All animal work was performed in compliance with the Dutch government guidelines.

Blood glucose concentrations were measured using a glucose meter (Accu-Chek; Roche, Basel, Switzerland). To prevent ketoacidosis and mortality, diabetic mice were treated when blood glucose levels were $>25 \mathrm{mmol} / \mathrm{L}$, with 1 to $2 \mathrm{U}$ of insulin (s.c.; Lantus; Aventis Pharmaceuticals, Bridgewater, NJ), maximally three times per week.

Systolic blood pressure was assessed with the noninvasive tail cuff system in conscious mice at the start and end of treatment, and at the end of the follow-up period, using the CODA system (Kent Scientific, Torrington, CT), according to manufacturer's instructions. $n=8$ per treatment group ( $n=7$ for nondiabetic Apoe $\mathrm{KO}$ mice).

\section{Urine Collection and Analysis}

Twenty-four-hour urine was collected at study start and after the 4-week treatment period. In a subset of animals, urine was also collected 4 weeks after termination of the treatment. Mice were acclimatized to metabolic cages, after which 24-hour urine was collected. Albumin levels were quantified with enzyme-linked immunosorbent assay (ELISA; Bethyl Laboratories, Montgomery, TX). Urinary creatinine levels were determined by the Jaffé method using $0.13 \%$ picric acid (Sigma-Aldrich), and quantified using a creatinine standard (Sigma-Aldrich) after ODs were measured with an ELISA plate reader. Urinary MCP-1 concentrations were quantified with ELISA (Anogen, Mississauga, Ontario, Canada), according to the protocol provided by the manufacturer.

\section{Immunohistochemistry}

Eight mice per treatment group were anesthetized by isoflurane inhalation and perfused via the left ventricle with 
HEPES-buffered salt solution containing $0.5 \%$ bovine serum albumin and $5 \mathrm{U} / \mathrm{mL}$ heparin to remove blood. Kidney capsules were removed, and half of the right kidney was fixed in paraformaldehyde solution (4\%) for 1 to 2 hours, followed by paraffin embedding for periodic acid-Schiff and trichrome staining and quantification of macrophages. The proportion of the glomerulus positive for periodic acid-Schiff stain was determined according to Animal Models of Diabetic Complications Consortium protocols, using color deconvolution in ImageJ version $1.49 \mathrm{~m}(\mathrm{NIH}$, Bethesda, MD; http://imagej.nih.gov/ij) to determine mesangial area.

The other half was snap frozen in 2-methylbutane (Sigma-Aldrich) for immunofluorescence staining. Frozen kidney sections $(4 \mu \mathrm{m}$ thick) were fixed in acetone for 10 minutes at room temperature. Nonspecific antibody binding was prevented by incubation with normal goat serum (4\%) in phosphate-buffered saline for 30 minutes. Glomerular heparanase expression was detected after overnight incubation with primary antibody (polyclonal rabbit antiheparanase; InSight Biopharmaceuticals, Rehovot, Israel) in combination with mouse pan-endothelial cell marker (BD Biosciences, San Jose, CA), followed by fluorescent-labeled secondary antibody for 1 hour, both in blocking buffer. Sections were counterstained with Hoechst (1:1000) and embedded in Vectashield mounting medium (Vector Laboratories Inc., Burlingame, CA). Cathepsin L polyclonal antibody (R\&D Systems Europe Ltd., Abingdon, UK) was incubated overnight, followed by horseradish peroxidase-conjugated secondary antibody and diaminobenzidine. Glomerular staining area was quantified on blinded sections, as percentage stained area/glomerular area, using ImageJ.

Glycocalyx composition was further analyzed on paraffin-embedded sections with antibodies against heparan sulfate [10E4 (AMS-Biotechnology, Bioggio-Lugano, Switzerland) and JM403 (a gift from Dr. Johan van der Vlag, Radboud University Medical Center)] and chondroitin sulfate (CS56; AMS-Biotechnology).

Podocytes were quantified after being identified with Wilms tumor- 1 antibody $(0.5 \mathrm{mg} / \mathrm{mL}$; Santa Cruz Biotechnology, Dallas, TX) in paraffin-embedded sections. Podocyte damage was further investigated in frozen kidney sections by incubation with primary antibodies against mouse synaptopodin (Progen Biotechnik GmbH, Heidelberg, Germany) or nephrin (R\&D Systems Europe Ltd.), followed by fluorescent-labeled secondary antibody for 1 hour. Staining intensity was quantified as percentage stained area/glomerular area in ImageJ.

Macrophages were identified using a rat monoclonal antibody against mouse F4/80 (Abcam, Cambridge, MA), recognizing most mouse macrophages ${ }^{20}$; a rabbit polyclonal antibody against mouse mannose receptor CD206 (Abcam), expressed specifically by regulatory macrophages $^{21}$; and a rat monoclonal antibody against mouse CD107b (Mac3; M3/84; BD-Biosciences Europe, Vianen, the Netherlands). The number of macrophages present was quantified in a minimum of 25 glomeruli per mouse or in 10 nonoverlapping high-power fields in case of tubulointerstitium ( $n=5$ to 8 per group for all immunohistochemical analyses, unless stated otherwise).

\section{Determination of Glomerular Endothelial Glycocalyx Coverage}

Glomerular endothelial glycocalyx coverage was determined with electron microscopy, as previously described. ${ }^{15}$ In short, the left kidney of three mice per group was perfused with $0.5 \%$ bovine serum albumin and $5 \mathrm{U} / \mathrm{mL}$ heparin in $5 \mathrm{~mL}$ HEPES-buffered salt solution at $2 \mathrm{~mL} /$ minute to remove blood, followed by $2 \mathrm{~mL}$ of cationic ferritin (horse spleen, $2.5 \mathrm{mg} / \mathrm{mL}$; Electron Microscopy Sciences, Fort Washington, PA) in HEPES-buffered salt solution alone at $2 \mathrm{~mL} /$ minute. Kidneys were fixated with $1.5 \%$ glutaraldehyde plus 1\% paraformaldehyde (both from Electron Microscopy Sciences, Hatfield, PA) in $0.1 \mathrm{~mol} / \mathrm{L}$ sodium-cacodylate buffered solution $(\mathrm{pH} 7.4)$ overnight at $4^{\circ} \mathrm{C}$. The kidney was subsequently divided into sections (180 $\mu \mathrm{m}$ thick), rinsed twice with $0.1 \mathrm{~mol} / \mathrm{L}$ sodiumcacodylate buffered solution, and postfixed in $1 \%$ osmium tetroxide and $1.5 \%$ potassium ferrocyanide on ice. Finally, samples were washed, dehydrated, embedded in epon, and polymerized at $60^{\circ} \mathrm{C}$ for 48 hours. Sections ( $100 \mathrm{~nm}$ thick) were further stained with 7\% uranyl acetate and Reynold's lead citrate. Transmission electron microscopy data were collected at an acceleration voltage of $120 \mathrm{kV}$ on a Tecnai G2 Spirit BioTWIN microscope (FEI, Eindhoven, the Netherlands), equipped with an FEI 4k Eagle chargecoupled device camera. Extensive sets of images were automatically acquired with $\times 18,500$ magnification, and combined using stitching software. ${ }^{22}$ The resulting large digital image provides an overview of the glomerulus, in which one can zoom into high detail, allowing for quantitative analyses. The previously perfused cationic ferritin binds to the polyanionic glycocalyx, which thereby can be visualized. Within the stitches, individual capillary loops were captured and glycocalyx coverage was quantified in eight to nine capillary loops in three glomeruli per mouse ( $n=3$ per group). The percentage of positive coverage of the endothelium with cationic ferritin was determined using an automatic grid overlay in the public domain ImageJ version 1.46. For every glomerulus, a minimum of 80 crosshairs were at the intersection of endothelium and scored for percentage positive.

\section{Ex Vivo Macrophage Phenotype in Kidney and Peripheral Blood}

Three kidneys per treatment group were perfused with HEPES-buffered salt solution containing $0.5 \%$ bovine serum albumin and $5 \mathrm{U} / \mathrm{mL}$ heparin to remove blood and stored in ice-cold phosphate-buffered saline. Kidneys were 
cut into small pieces and digested with $1.6 \mathrm{mg} / \mathrm{mL}$ collagenase type 1A (Sigma-Aldrich) and $60 \mathrm{U} / \mathrm{mL}$ DNase I (Sigma-Aldrich) solution for 30 minutes at $37^{\circ} \mathrm{C}$. Tissues were minced through a $100-\mu \mathrm{m}$ cell strainer and subsequently a $40-\mu \mathrm{m}$ cell strainer (BD Biosciences) to obtain a single cell suspension. The labeling and gating strategy is detailed in Supplemental Figure S1. For comparison of mean fluorescence intensities between the different samples (blood, spleen, and kidney cells), a stain index was used, given as $\left(\right.$ mean $_{\text {positive }}-$ mean $\left._{\text {background }}\right) / 2 \times\left(\mathrm{SD}_{\text {background }}\right)$, in which the lymphocyte population is used as background (negative for CCR2). ${ }^{23}$ A subset of cells was counted on an LSRII flow cytometer (BD Biosciences), and data were analyzed using FACSDiva software version 6.1.2 (BD Biosciences). Peripheral blood, drawn from the tail vein, was analyzed accordingly.

The remaining renal cells were sorted on a BD FACSAri III (BD Biosciences) (Supplemental Figure S1). CD11b ${ }^{+}$, $\mathrm{B} 220^{-}, \mathrm{Lyc}^{-} \mathrm{G}^{-}$, and $\mathrm{F} 4 / 80^{+}$macrophages were isolated and cultured in a 96-well plate at a density of 10,000 cells/ well in Iscove's modified Dulbecco's medium supplemented with $10 \%$ fetal calf serum, $100 \mathrm{U} / \mathrm{mL}$ penicillin, and $100 \mathrm{mg} / \mathrm{mL}$ streptomycin. Cells were maintained at $37^{\circ} \mathrm{C}$ in a humidified atmosphere of $5 \% \mathrm{CO}_{2}$. After 1 hour, cells were stimulated with $1 \mu \mathrm{g} / \mathrm{mL}$ lipopolysaccharide for 24 hours. Supernatant was analyzed for IL-6, IL-10, and tumor necrosis factor (TNF)- $\alpha$ (BD Biosciences) levels with ELISA, as well as for secreted cathepsin L activity (Abcam), according to the manufacturer's protocol.

\section{Statistical Analysis}

Data are presented as means $\pm \mathrm{SD}$. Changes in continuous variables during treatment were analyzed using two-way analysis of variance with post hoc Tukey's multiplecomparison analysis in GraphPad Prism version 6 (GraphPad Prism Software, Inc., San Diego, CA). This takes into account that samples over time from the same animal are not independent. Differences in other experiments were determined using analysis of variance and post hoc analyses with Tukey's multiple comparison test. Comparison of expression between two different groups was evaluated using a $t$-test. $P<0.05$ was considered statistically significant.

\section{Results}

\section{MCP-1 Inhibition Does Not Affect the Diabetes Characteristics in Streptozotocin-Treated Apoe KO Mice}

Blood glucose levels in Apoe KO mice after streptozotocin treatment, and cholesterol $(0.15 \%)$-enriched diet, were elevated during the 12 weeks up to the start of mNOX-E36 treatment $(9.9 \pm 1.4$ to $24.5 \pm 6.3 \mathrm{mmol} / \mathrm{L})$ (Figure 1A). Similar to previous mNOX-E36 studies, ${ }^{11,19,24}$ treatment with $20 \mathrm{mg} / \mathrm{kg}$ mNOX-E36, or nonfunctional Spiegelmer as a control, for 4 weeks resulted in pharmacologically relevant plasma levels (data not shown). This 4-week mNOX-E36 intervention did not affect the blood glucose levels $(27.4 \pm 5.4$ versus
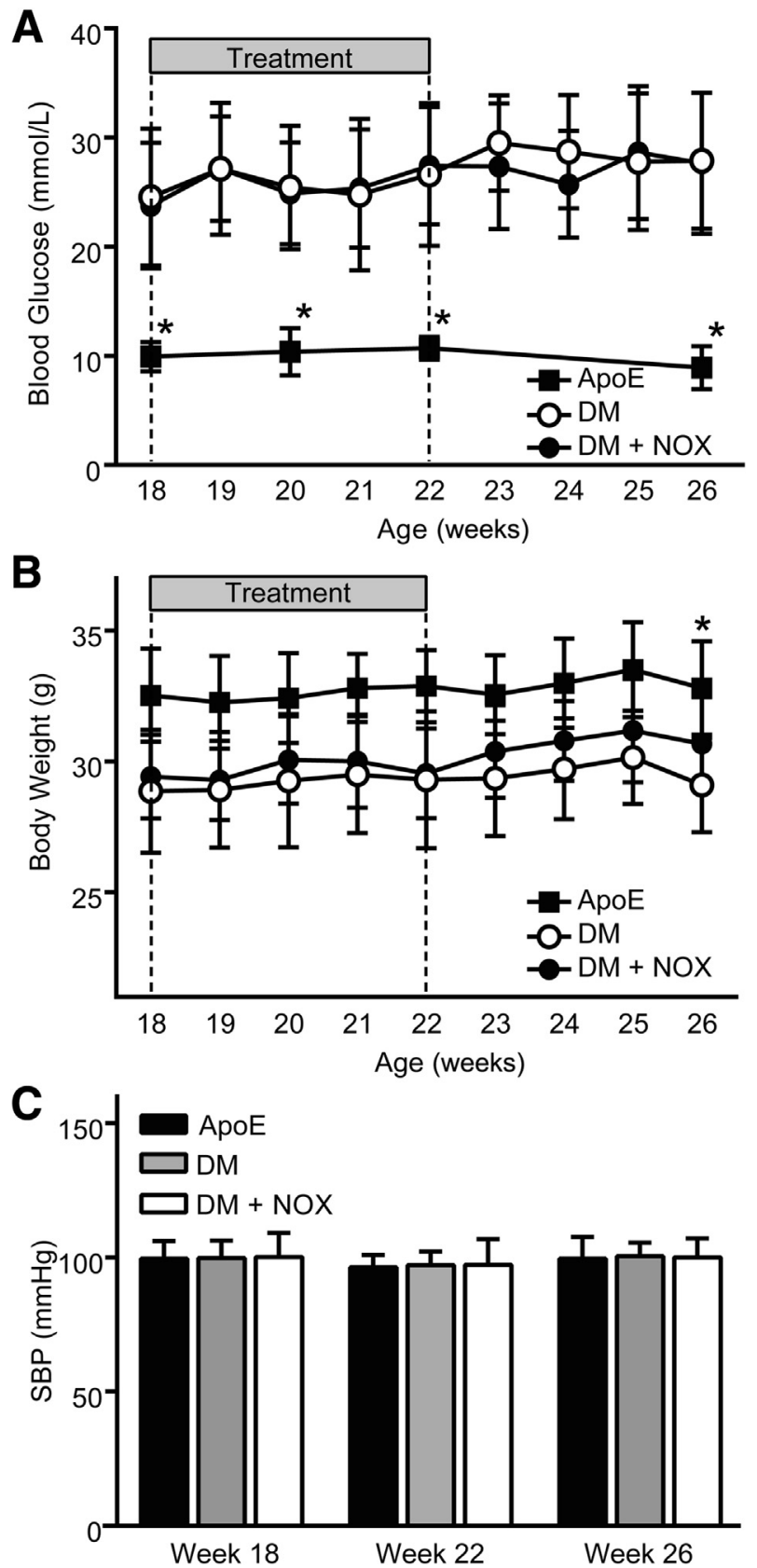

Figure 1 Monocyte chemotactic protein-1 inhibition does not change diabetic characteristics in Apoe knockout (KO) mice. A: Blood glucose levels increase in diabetic Apoe $\mathrm{KO}$ mice and do not change during and after treatment. B: Body weight slightly decreases on induction of diabetes, but does not change during and after treatment. C: Diabetes and (rev)mNOX-E36 treatment do not alter systolic blood pressure (SBP). Data are expressed as means \pm SD. $n=13$ [A and B, Apoe K0 mice (ApoE)]; $n=23[\mathbf{A}$ and $\mathbf{B}$, diabetic Apoe KO mice treated with inactive revmNOX-E36 (DM) and diabetic Apoe K0 mice treated with mNOX-E36 (DM + NOX) at week 22]; $n=10$ (A and B, DM at week 26); $n=11$ (A and B, DM + NOX at week 26); $n=7$ $($ C, apoE) $; n=8[$ C, DM $+($ rev)mNOX-E36 at week 22]; $n=5[$ C, DM $+($ rev $)$ mNOX-E36 at week 26]. ${ }^{*} P<0.05$ versus $\mathrm{DM} \pm$ mNOX-E36. 

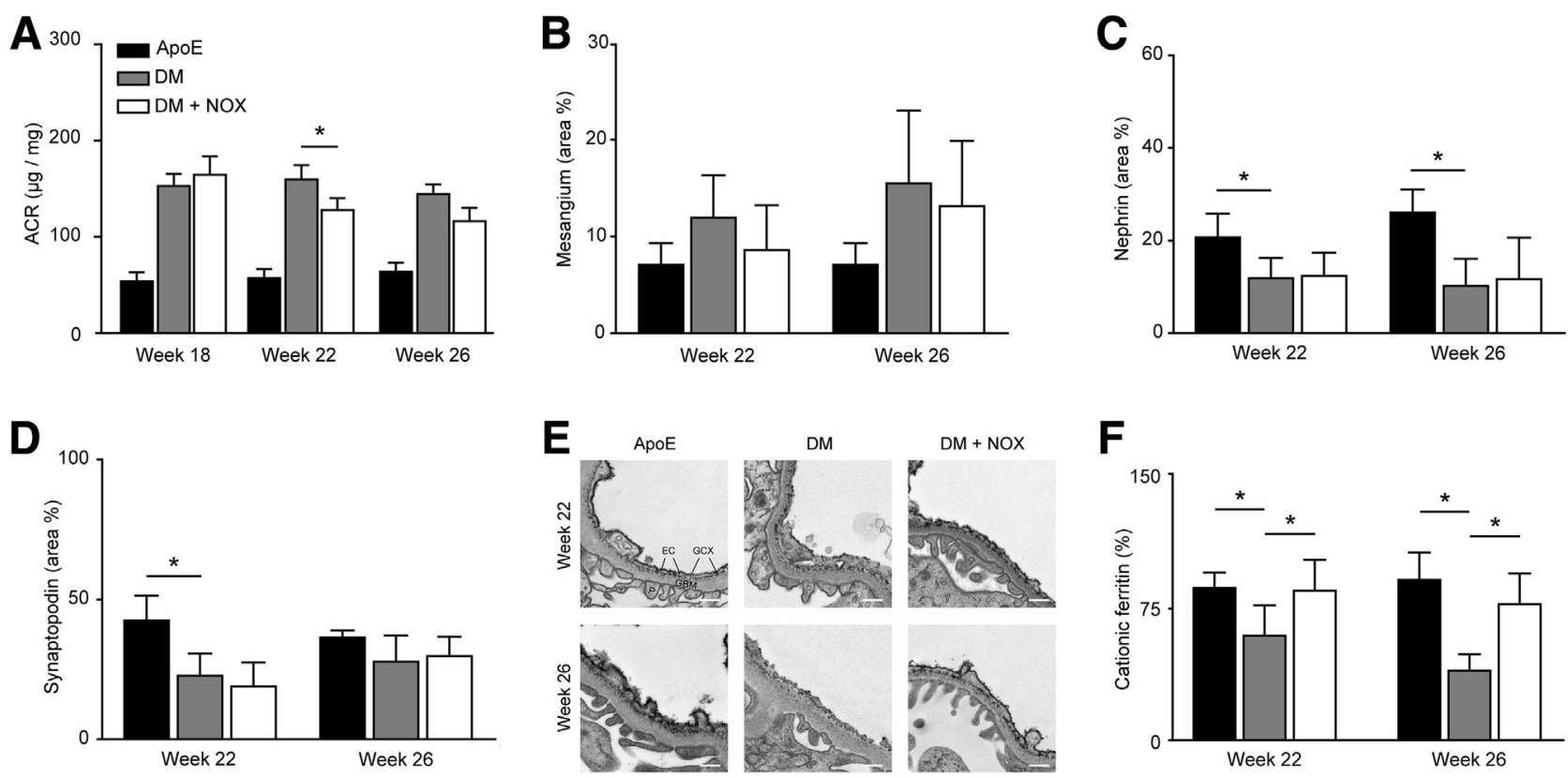

Figure 2 Monocyte chemotactic protein-1 inhibition reduces albuminuria in diabetic Apoe knockout (K0) mice. A: Urinary albumin/creatinine ratios (ACRs) at baseline (week 18), 4 weeks of treatment (week 22), and after 4 weeks of follow-up (week 26). B: Mesangial area is not affected by treatment, as measured by percentage periodic acid-Schiff-positive area per glomerulus. C and D: Nephrin (C) and synaptopodin (D) are expressed as percentage glomerular area. Both are not affected by treatment. E: Representative transmission electron microscopic images of cationic ferritin bound to the negatively charged endothelial glycocalyx in glomeruli. F: Quantification of endothelial cationic ferritin coverage in capillary loops in nine glomeruli of three mice, shown as percentage of total capillary length. Significance compared with Apoe KO mice (ApoE) and diabetic Apoe K0 mice treated with mNOX-E36 (DM + NOX). Data are expressed as means \pm SD. $n=13(\mathbf{A}, \mathrm{ApoE}) ; n=23$ [A, DM and diabetic Apoe K0 mice treated with mNOX-E36 (DM + NOX) at week 22]; $n=10($ A, DM at week 26); $n=11$ (A, DM + NOX at week 26); $n=8$ per group (B); $n=5$ to 8 per treatment group (C and D). * $P<0.05$. EC, endothelium; GBM, glomerular basement membrane; $G C X$, cationic ferritin bound to endothelial glycocalyx; $P$, podocyte. Scale bars $=500 \mathrm{~nm}(\mathrm{E})$.

$26.6 \pm 6.5 \mathrm{mmol} / \mathrm{L}$ for control), and levels remained high during the 4 weeks of follow-up (mNOX-E36 versus control, $27.7 \pm 6.5$ versus $27.9 \pm 6.2 \mathrm{mmol} / \mathrm{L})$. In contrast, in nondiabetic Apoe $\mathrm{KO}$ mice receiving normal chow, blood glucose levels remained low during the entire experimental period (week 22, $10.7 \pm 1.0 \mathrm{mmol} / \mathrm{L}$; and week $26,8.1 \pm 2.0 \mathrm{mmol} / \mathrm{L}$ ).

At the end of the 4-week intervention (week 22 of age), the body weight of mNOX-E36-treated mice was comparable to control-treated mice $(29.5 \pm 1.7$ versus $29.3 \pm 2.6 \mathrm{~g}$ ) (Figure 1B), both of which were lower than nondiabetic Apoe $\mathrm{KO}$ mice $(32.53 \pm 1.4 \mathrm{~g} ; P<0.05)$. No change in body weight was observed at the end of the follow-up period (mNOX-E36 versus control, $30.6 \pm 1.8$ versus $29.1 \pm 1.8 \mathrm{~g}$ ), which was still lower compared with nondiabetic Apoe $\mathrm{KO}$ mice $(32.8 \pm 1.8 \mathrm{~g}$; $P<0.05)$.

To assess whether our observations are independent of changes in blood pressure, we measured systolic blood pressure before and after treatment and at the end of the follow-up period. No changes in systolic blood pressure were observed between diabetic and nondiabetic mice $(99.5 \pm 6.6$ versus $99.8 \pm 6.5 \mathrm{mmHg}$ at week 18$)$ and after the entire experimental period (mNOX-E36 versus control, $97.1 \pm 5.1$ versus $97.2 \pm 9.7 \mathrm{mmHg}$ at 22 weeks of age, and
$100.4 \pm 5.1$ versus $100.0 \pm 7.2 \mathrm{mmHg}$ at 26 weeks of age) (Figure 1C).

\section{MCP-1 Inhibition Reduces Albuminuria and Restores the Glomerular Endothelial Glycocalyx}

Treatment of diabetic Apoe KO mice for 4 weeks with mNOX-E36 reduced the albumin/creatinine ratio to $118.6 \pm 11.9 \mu \mathrm{g} / \mathrm{mg}$ in comparison to treatment with control Spiegelmer $(157.9 \pm 19.4 \mu \mathrm{g} / \mathrm{mg} ; P<0.05)$ (Figure 2A). Nondiabetic control mice had an albumin/ creatinine ratio of $58.5 \pm 13.2 \mu \mathrm{g} / \mathrm{mg}$. Because MCP-1 inhibition in diabetic patients revealed a strong legacy effect with regard to reduced albuminuria, ${ }^{14}$ we also investigated albumin leakage after a 4-week follow-up period. Four weeks after cessation of mNOX-E36 treatment, mice still showed a trend toward a lower albumin/ creatinine ratio compared to control-treated diabetic mice $(132.4 \pm 17.8$ versus $98.8 \pm 15.2 ; P=0.180)$. After mNOX-E36 treatment and the follow-up period, no changes were observed in mesangial area in comparison to control diabetic Apoe $\mathrm{KO}$ mice (mNOX-E36 versus control, $8.6 \% \pm 4.6 \%$ versus $11.9 \% \pm 4.4 \%$ ) (Figure $2 \mathrm{~B}$ ). With respect to podocyte injury, no changes were found in the number of Wilms tumor-1-positive podocytes or 

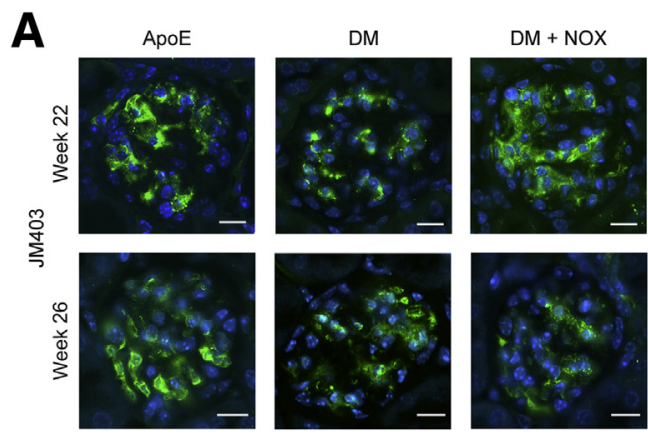

B
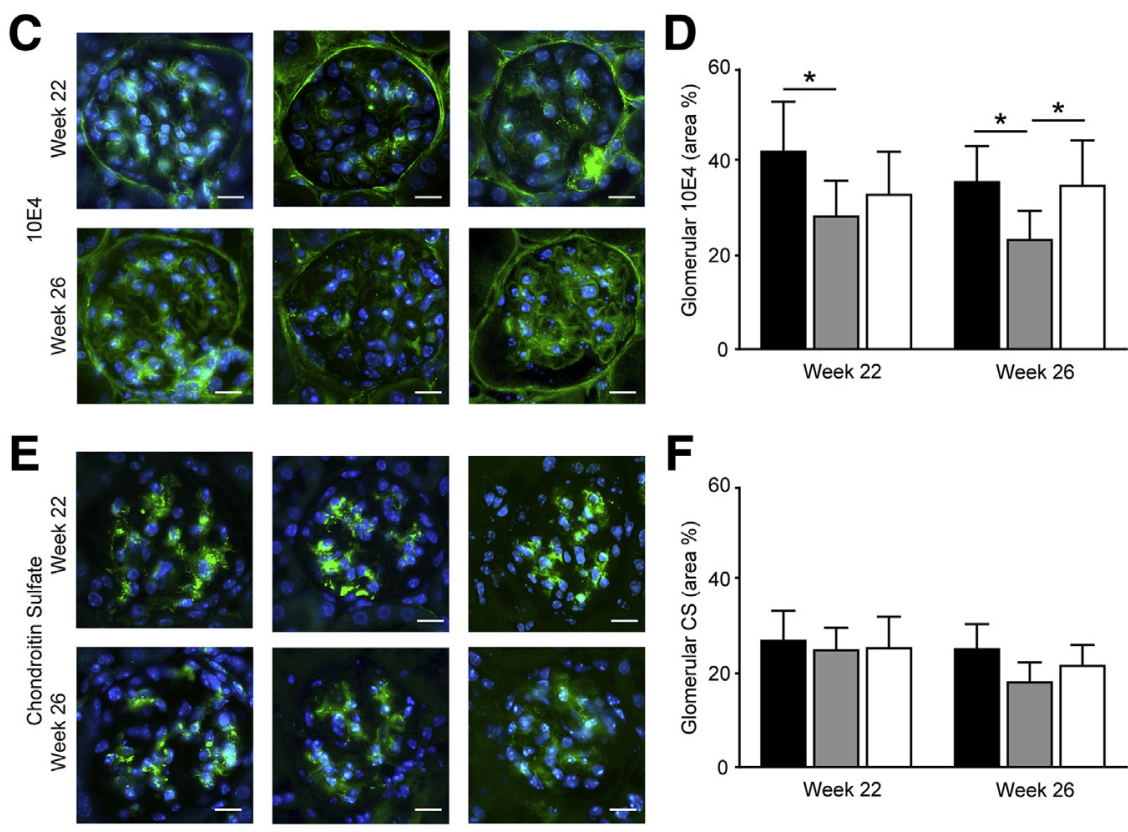

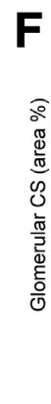

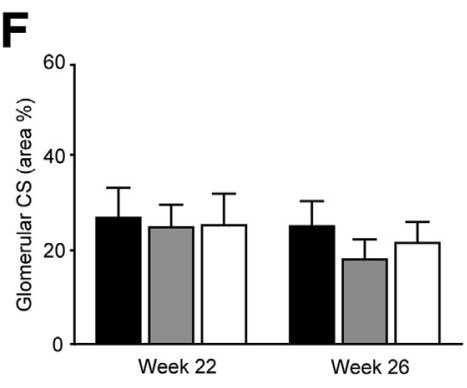

Figure 3 Monocyte chemotactic protein-1 inhibition changes glomerular heparan sulfate expression. A, C, and E: Representative images of glomerular JM403 (A), 10E4 (C), and chondroitin sulfate (CS; E) expression in Apoe knockout (KO) mice (ApoE) and diabetic Apoe KO mice treated with inactive revmNOX-E36 (DM) or active mNOXE36 (DM + NOX). B, D, and F: Quantification of glomerular expression is shown. Data are expressed as means \pm SD (percentage positivity). $n=5$ to 8 per treatment group. ${ }^{*} P<0.05$. Scale bars $=$ $20 \mu \mathrm{m}(\mathbf{A}, \mathbf{C}$, and $\mathbf{E})$. expression of slit diaphragm proteins nephrin and synaptopodin on MCP-1 inhibition (Figure 2, C and D). Furthermore, mNOX-E36 did not prevent interstitial tubular epithelial injury, as indicated by similar urinary kidney injury molecule-1 excretion levels (data not shown).

Urinary MCP-1 concentrations were lower than the detection limit of our assays $(<15.6 \mathrm{pg} / \mathrm{mL})$ in nondiabetic Apoe $\mathrm{KO}$ mice as well as diabetic Apoe $\mathrm{KO}$ mice. This is in support of the concept that our observations can be best explained by local changes at the tissue level. However, increased MCP-1 concentrations were observed in the mice treated with mNOX-E36 after 4 weeks of treatment $(40.2 \pm 15.8 \mathrm{pg} / \mathrm{mL})$, whereas these levels were diminished 4 weeks after termination of treatment $(<15.6 \mathrm{pg} / \mathrm{mL})$. These findings are in line with previous observations by Darisipudi et al. ${ }^{12}$ They demonstrated that mNOX-E36 forms an inactive complex with its molecular target (MCP-1), which is cleared much slower than MCP-1, and is detectable in the ELISA. In this case, MCP-1 levels, therefore, reflect the pharmacodynamics of the compound.

Next, we tested the effect of mNOX-E36 treatment on the glomerular endothelial glycocalyx coverage, being the first layer in the glomerular filtration barrier. This was visualized and quantified by cationic ferritin binding to the negatively charged glomerular endothelial glycocalyx (Figure 2E). Renal perfusion resulted in cationic ferritin binding to the luminal endothelial cell surface, but also directly underneath the endothelium. The latter served as an endogenous control: only capillaries that showed cationic ferritin on the surface of the endothelium and/or in the glomerular basement membrane were used for analysis. Diabetes resulted in less endothelial coverage at 22 weeks of age $(57.3 \% \pm 20.2 \%)$ compared with nondiabetic Apoe $\mathrm{KO}$ mice $(83.6 \% \pm 8.4 \%$ ) (Figure $2 \mathrm{~F}$ ). Treatment with mNOXE36 increased glomerular glycocalyx coverage to a percentage comparable to nondiabetic glomeruli (81.9\% $\pm 17.1 \% ; P<0.05)$. Interestingly, although the endothelial glycocalyx has a high turnover, its recovery on treatment remained visible 4 weeks after treatment, pointing toward a legacy effect of the treatment. At week 26, cationic ferritin coverage in control-treated diabetic mice was reduced $(37.0 \% \pm 9.2 \% ; P<0.05)$ compared with nondiabetic Apoe $\mathrm{KO}$ mice, whereas coverage in mNOXE36-treated mice still remained higher compared with control-treated diabetic mice $(74.7 \% \pm 16.9 \% ; P<0.05)$. 

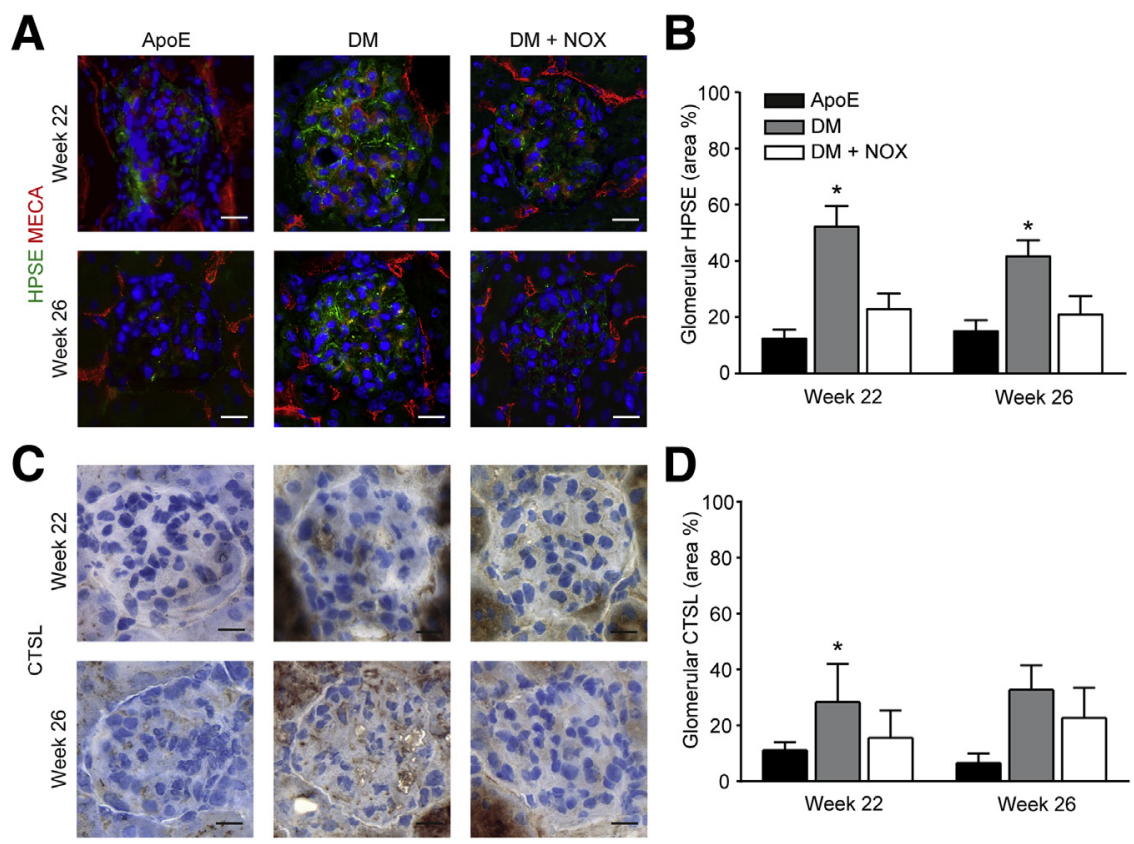

Figure 4 Monocyte chemotactic protein-1 inhibition reduces glomerular heparanase-1 (HPSE) and cathepsin L expression. A and C: Representative images of glomerular heparanase $(\mathbf{A})$ and cathepsin L (CTSL; C) expression in Apoe KO mice (ApoE) and diabetic Apoe K0 mice treated with inactive revmNOX-E36 (DM) or active mNOX-E36 (DM + NOX). B and D: Quantification of glomerular expression shown as percentage positivity. Data are expressed as meas \pm SD. $n=5$ to 8 per treatment group (B and $\mathbf{D})$. ${ }^{*} P<0.05$ versus $\mathrm{ApoE}$ and DM + NOX. Scale bars $=20 \mu \mathrm{m}(\mathbf{A}$ and $\mathbf{C})$.
The changes in glomerular endothelial glycocalyx coverage were further analyzed with respect to specific glycocalyx heparan and chondroitin sulfate composition. Heparan sulfate structures were analyzed using 10E4 and JM403 antibodies, recognizing so-called mixed heparan sulfate domains, containing both $\mathrm{N}$-acetylated and $\mathrm{N}$ sulfated disaccharide units (10E4) or N-unsubstituted glucosamine residues (JM403), respectively. Diabetes reduced glomerular JM403 expression to $23.7 \% \pm 7.6 \%$, whereas in mNOX-E36-treated mice, expression was higher $(33.1 \% \pm 8.0 \% ; P<0.05)$, comparable to nondiabetic mice (Figure 3, A and B). 10E4 levels were reduced in diabetic mice, but in mNOX-E36-treated mice, they were comparable to nondiabetic mice (Figure 3, C and D). Four weeks after cessation of treatment, there was still a legacy effect with respect to both the diabetes effect on heparan sulfate composition and the amelioration by mNOX-E36. Chondroitin sulfate expression was neither affected by diabetes nor by mNOX-E36 treatment at all points measured (Figure 3, E and F).

\section{MCP-1 Inhibition Reduces Heparanase and Cathepsin L Expression}

The glycocalyx consists of multiple glycoproteins and glycosaminoglycans, of which heparan sulfates are the most dominant. To analyze the mechanism of restored glycocalyx dimensions on treatment, we looked at the expression of the heparan sulfate-degrading enzyme heparanase. Diabetic mice show increased glomerular heparanase protein expression compared with nondiabetic Apoe KO mice $(48.9 \% \pm 20.9 \%$ versus $12.7 \% \pm 9.3 \% ; P<0.05)$ (Figure 4, A and B). Treatment of diabetic mice with mNOX-E36 effectively reduced glomerular heparanase protein expression to $25.4 \% \pm 13.8 \%(P<0.05)$. This effect remained present 4 weeks after treatment with mNOXE36 had stopped $(52.8 \% \pm 17.7 \%$ versus $22.6 \% \pm 18.2 \%$; $P<0.05)$. Secreted latent proheparanase is activated by cathepsin L. ${ }^{18,25}$ We previously showed by immunohistochemistry that the macrophage marker F4/80 colocalizes with cathepsin L. ${ }^{15}$ Together with the elevated heparanase expression, increased glomerular cathepsin $\mathrm{L}$ protein expression was observed in diabetic Apoe $\mathrm{KO}$ mice $(27.6 \% \pm 12.0 \%$ versus $11.1 \% \pm 2.8 \%$ in nondiabetic controls; $P<0.05$ ), and after treatment with mNOX-E26, a reduced cathepsin $\mathrm{L}$ expression was significantly reduced $(13.7 \% \pm 9.5 \% ; P<0.05)$ (Figure 4, C and D). However, 4 weeks after cessation of treatment, cathepsin L expression in the mNOX-E36-treated group was not significantly different from control-treated diabetic mice $(33.4 \% \pm 9.5 \%$ versus $22.9 \% \pm 11.9 \% ; P=0.105$ ).

\section{MCP-1 Inhibition Changes Macrophage Properties}

Inflammatory cells, such as monocytes and macrophages, can secrete cathepsin L. Although the number of peripheral blood monocytes did not change on treatment with mNOXE36 (FACS analysis and data not shown), a lower mean fluorescence intensity of CCR2 was observed (mNOX-E36 versus control treated, $181.5 \pm 132.3$ versus $437.5 \pm 282.6$ ) on the Ly6C ${ }^{\text {hi }}$ subset of monocytes (Supplemental Figure S2). These inflammatory-prone Ly6 $\mathrm{C}^{\text {hi }}$ monocytes, in particular, depend on MCP-1/CCR2 recruitment to inflamed tissues. ${ }^{26}$ In accordance, the reduced CCR2 expression on these cells correlated with increased chemokine (C-X3-C motif) receptor 1 or fractalkine receptor chemokine receptor 1 expression (Pearson $r=0.962$; $P=0.038 ;$ data not shown). ${ }^{27}$ 

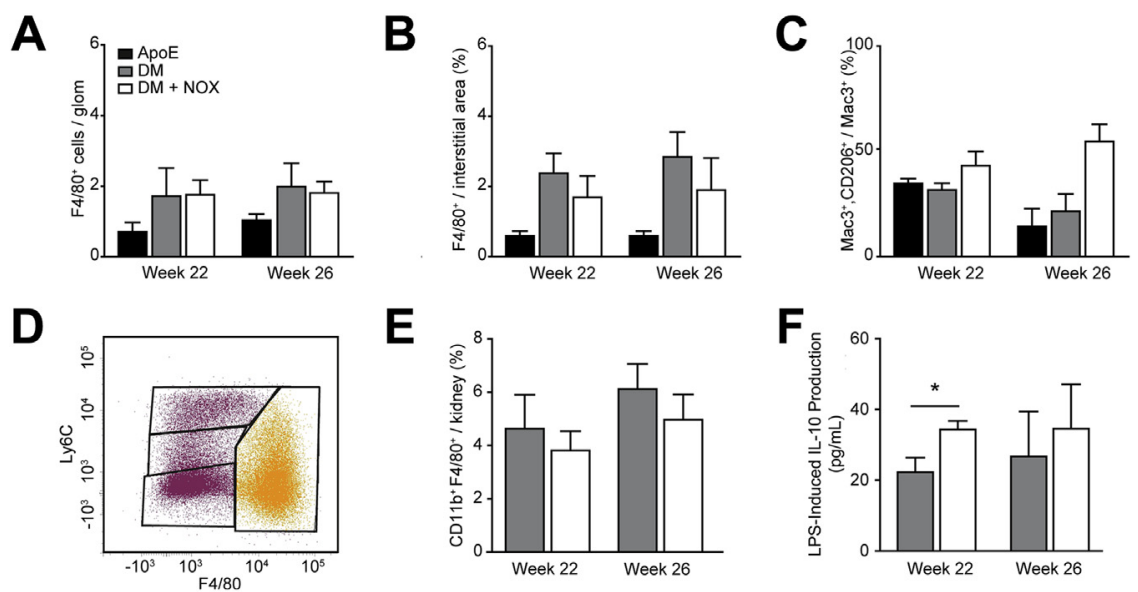

$E$
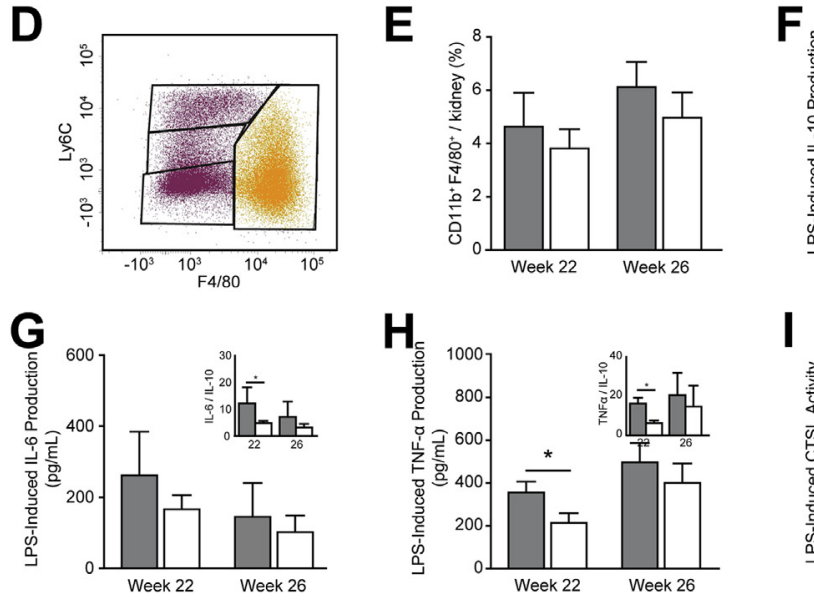

Figure 5 Monocyte chemotactic protein-1 inhibition changes glomerular macrophages toward a regulatory phenotype. $\mathbf{A}$ and $\mathbf{B}$ : The number of glomerular (A) and tubulointerstitial (B) $\mathrm{F} 4 / 80^{+}$ macrophages increases in diabetes, but does not differ between treatment groups. Macrophages were isolated from the kidney by fluorescenceactivated cell sorting (FACS), based on $\mathrm{CD} 11 \mathrm{~b}^{+} \mathrm{F} 4 / 80^{+}$positivity. C: The ratio of $\mathrm{MAC} 3$ and CD206 double-positive macrophages compared to MAC3-positive cells is affected by mNOX-E36. D: Representative FACS plot; orange dots are selected macrophages for isolation (used in E). E: Quantification of renal macrophages. F-H: IL-10, IL-6, and tumor necrosis factor (TNF)- $\alpha$ secretion by renal macrophages after ex vivo lipopolysaccharide (LPS) treatment for 24 hours. Insets in $\mathbf{G}$ and $\mathbf{H}$ show IL-6/IL-10 and TNF- $\alpha /$ IL-10 ratios, respectively. I: Cathepsin L (CTSL) activity in the supernatant of isolated macrophages was measured and expressed relatively to unstimulated macrophages. Data are expressed as means \pm SD. $n=3$ mice per group $(\mathbf{F}-\mathbf{I}) ; n=3-5$ mice per group $(\mathbf{E}) ; n=5$ -8 mice per group $(\mathbf{A}-\mathbf{C})$. ${ }^{\star} P<0.05$. ApoE, Apoe KO mice; DM, (macrophages isolated from) diabetic Apoe $\mathrm{KO}$ mice treated with inactive revmNOX-E36; DM + NOX, (macrophages isolated from) diabetic Apoe KO mice treated with mNOXE36; K0, knockout.
Immunohistochemistry revealed that the number of F4/ $80^{+}$macrophages in the tubulointerstitial and glomerular compartment was increased in diabetic mice compared with controls, but no change in absolute number of macrophages was observed on MCP-1 inhibition based on immunofluorescence (Figure 5, A and B). Further analysis of CD206 ${ }^{+} /$ $\mathrm{Mac}^{+}$cells showed that in mNOX-E36-treated mice, the ratio of $\mathrm{CD} 206^{+} / \mathrm{Mac}^{+}$over $\mathrm{Mac} 3^{+}$increased, revealing more regulatory macrophages within the glomeruli (week $22,46.8 \% \pm 12.4 \%$ versus $31.2 \% \pm 5.2 \%$; week 26 , $56.7 \% \pm 11.4 \%$ versus $28.1 \% \pm 10.1 \% ; P<0.05)$ (Figure 5C).

FACS analysis to quantify F4/80-positive macrophages in whole kidney confirmed this lack in change of absolute macrophage number (control versus mNOX-E36-treated mice, $4.6 \% \pm 2.5 \%$ versus $3.8 \% \pm 1.6 \%$ at week 22 and $6.1 \% \pm 1.6 \%$ versus $5.0 \% \pm 1.6 \%$ at week 26) (Figure 5, D and $\mathrm{E}$ ), as well as unchanged CCR2 expression of mono-

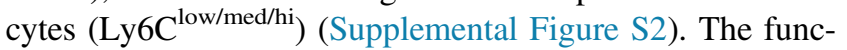
tional phenotype of renal macrophages was further analyzed in detail. Isolated renal $\mathrm{CD}_{11} \mathrm{~b}^{+}, \mathrm{B} 220^{-}, \mathrm{Lyc} 6 \mathrm{G}^{-}$, and F4/ $80^{+}$macrophages from diabetic mice treated with mNOXE36 or control Spiegelmer (Figure 5C and Supplemental Figure S1) were stimulated with lipopolysaccharide to determine their cytokine profile. Macrophages from mNOXE36-treated diabetic mice responded with increased production and release of IL-10 (from $18.8 \pm 4.6$ to $34.3 \pm 2.5$ $\mathrm{pg} / \mathrm{mL}$ ), which was higher compared to macrophages of control-treated mice $(22.3 \pm 4.1 \mathrm{pg} / \mathrm{mL} ; P<0.05)$ (Figure 5F). The production of IL-6, determined as an intermediate cytokine with both proinflammatory and anti-inflammatory effects, ${ }^{28}$ did not differ significantly between these groups (Figure 5G). However, release of the proinflammatory cytokine TNF- $\alpha$ was significantly decreased on treatment with mNOX-E36 (mNOX-E36 versus control, $214.4 \pm 45.2$ versus $356.1 \pm 50.8 \mathrm{pg} / \mathrm{mL}$; $P<0.05$ ) (Figure $5 \mathrm{H}$ ). Accordingly, the reduction in individual IL-6/IL-10 (Figure 5G) and TNF- $\alpha /$ IL-10 ratios (Figure $5 \mathrm{H}$ ) confirmed the overall anti-inflammatory cytokine expression of renal macrophages after treatment with mNOX-E36. Moreover, lipopolysaccharide induced a $20.7 \% \pm 3.7 \%$ increase in active cathepsin $\mathrm{L}$ release, which was reduced by mNOX-E36 to $10.1 \% \pm 4.2 \%$ (Figure $5 \mathrm{I}$ ).

In addition, mNOX-E36 exerted a similar effect on cathepsin L secretion by murine RAW264.7 macrophages after MCP-1 and lipopolysaccharide stimulation (Supplemental Figure S3). Thus, mNOX-E36 can directly reduce the capacity of macrophages to secrete cathepsin L.

\section{Discussion}

In the present study, we show that MCP-1 inhibition in diabetic nephropathy effectively reduces albuminuria in association with restoration of glomerular endothelial glycocalyx dimensions. This effect was observed in the absence of hemodynamic changes and in the presence of podocyte injury, underlining the importance of the glomerular endothelial glycocalyx for its barrier function. MCP-1 inhibition was also accompanied by a reduction in 
glomerular cathepsin $\mathrm{L}$ and heparanase expression in vivo, as well as a shift toward anti-inflammatory resident renal macrophages, as we could show functionally after ex vivo stimulation. One aspect of this polarization of macrophage function by MCP-1 inhibition is a decreased ability to secrete cathepsin L.

In a diabetic milieu, the glycocalyx is degraded in a heparanase-dependent manner. ${ }^{17,29}$ In our model, this was reflected by selective changes in heparan sulfate structures as well as reduction of $\mathrm{N}$-unsubstituted glucosamine domains, whereas chondroitin sulfates did not change. In glomeruli, heparanase is produced as inactive proheparanase by podocytes, endothelial cells, and platelets. ${ }^{30}$ Activation of proheparanase generally occurs after uptake into the early endosome and lysosome through cathepsin L. ${ }^{31}$ Cathepsin L proteolytically activates proheparanase into its active heparan sulfate-degrading form, ${ }^{25}$ after which heparanase serves intracellular regulatory processes. ${ }^{32}$ However, macrophages also secrete cathepsin L during lysosomal delivery, thus allowing the activation of proheparanase in the extracellular environment. ${ }^{33,34}$ This process can be further accelerated by diabetes-induced changes in the extracellular matrix, ${ }^{35}$ as well as by active heparanase itself that activates macrophages by inducing Toll-like receptor signaling. ${ }^{29}$

Monocytes high in CCR2 expression (Ly6C ${ }^{\text {hi }}$ subset) exhibit proinflammatory properties. ${ }^{27}$ mNOX-E36 reduces CCR2 expression in peripheral circulating monocytes in our study, as was observed in the clinical study, ${ }^{14}$ suggesting less inflammatory potential and less sensitivity toward MCP-1 gradients in tissue. ${ }^{4}$ Nevertheless, tissue levels in the spleen and kidney of these CCR2-expressing monocytes were not reduced. Yet, we found that mNOXE36 markedly changed the functional behavior of resident kidney macrophages: Although there was no difference in total number of renal macrophages, their differentiation and function had changed after MCP-1 inhibition. mNOX-E36 induced an anti-inflammatory phenotype of the renal macrophages. For example, the capacity to produce TNF- $\alpha$ was reduced, which is relevant as TNF- $\alpha$ induces heparanase gene expression in mouse glomerular endothelial cells and podocytes. ${ }^{36}$ Moreover, there was a reduction in the release of cathepsin L, the enzyme that has been shown to be essential in the development of diabetic nephropathy. ${ }^{18}$ TNF- $\alpha$-induced cathepsin L in macrophages ${ }^{37}$ contributes to the vicious circle of self-stimulation of macrophages.

Podocytes also have been shown to express the CCR2 receptor. ${ }^{38}$ This suggests that MCP-1 could possibly have influenced glomerular filtration barrier function via podocytes as well. In our current study, however, MCP-1 inhibition neither restored diabetes-induced decrease of slit diaphragm proteins nephrin and synaptopodin nor affected the number of podocytes. In podocytes, cathepsin L is involved in breakdown of synaptopodin, ${ }^{18,39}$ but apparently, this process was not ameliorated by MCP-1 inhibition. These data suggest that mNOX-E36 did not reduce albuminuria by improving podocyte function.
Interestingly, there appears to be a treatment legacy effect on some parameters in this study, at 4 weeks after cessation of treatment. More specifically, heparanase expression was still reduced and the glycocalyx and heparan sulfate composition was still preserved. This further corroborates the fact that the effects of MCP-1 inhibition are independent of hemodynamic changes and are related to (ultra)structural glomerular restoration. These findings on treatment legacy were also noted in the clinical study in which emapticap pegol-induced beneficial effects on albumin/creatinine ratio and $\mathrm{HbAlc}$, without hemodynamic changes, were maintained on termination of treatment. ${ }^{14}$ The presence of MCP-1-mNOX-E36 complexes in the urine up to 4 weeks after treatment further suggests a prolonged pharmacodynamic effect of this compound. Together, MCP-1 blockade has additional potential in the treatment of diabetic nephropathy, where therapeutic options are currently still limited. This notion is supported by observations in human diabetic nephropathy, where increased renal and urinary MCP-1 levels have been found, ${ }^{40}$ and provides a mechanism of action for recent observations in human diabetic nephropathy, where blockade of MCP-1 reduced albuminuria. ${ }^{14}$

In conclusion, we found persistent restoration of the glomerular endothelial glycocalyx in diabetic nephropathy with MCP-1 inhibition. Our data suggest that interference with macrophage function attenuates the degradation of the glycocalyx by heparanase, resulting in less albuminuria.

\section{Acknowledgments}

We thank Prof. Abraham J. Koster (Leiden University Medical Center) for the use of the electron microscope facilities, Dr. van der Vlag for JM403 antibody, and NOXXON Pharma AG (Berlin, Germany) for providing mNOX-E36 and for analysis of mNOX-E36 plasma levels.

M.G.S.B. and D.H.T.IJ. designed experiments, researched and analyzed data, and wrote and revised the manuscript; A.K., M.C.A., W.M.P.J.S., G.W., and A.M.v.O.-R. acquired and interpreted data and critically revised the manuscript; A.J.v.Z., H.C.d.B., J.v.d.V., C.v.K., and D.E. critically revised the manuscript for important intellectual content; B.M.v.d.B., D.H.T.IJ., and T.J.R. conceived, designed, and supervised the study, and critically revised the manuscript; T.J.R. is the guarantor of this work and, as such, had full access to all the data in the study and takes responsibility for the integrity of the data and the accuracy of the data analysis.

\section{Supplemental Data}

Supplemental material for this article can be found at http://dx.doi.org/10.1016/j.ajpath.2017.07.020. 


\section{References}

1. US Renal Data System Annual Data Report. Atlas of Chronic Kidney Disease and End-Stage Renal Disease in the United States. Edited by National Institutes of Health. Bethesda, MD: National Institute of Diabetes and Digestive and Kidney Diseases, 2016. Available at https://www.usrds.org/adr.aspx

2. Heerspink HJ, De Zeeuw D: Novel anti-inflammatory drugs for the treatment of diabetic kidney disease. Diabetologia 2016, 59: $1621-1623$

3. Van Coillie E, Van Damme J, Opdenakker G: The MCP/eotaxin subfamily of CC chemokines. Cytokine Growth Factor Rev 1999, 10: 61-86

4. Haller H, Bertram A, Nadrowitz F, Menne J: Monocyte chemoattractant protein-1 and the kidney. Curr Opin Nephrol Hypertens 2016, 25:42-49

5. Biswas SK, Sodhi A, Paul S: Regulation of nitric oxide production by murine peritoneal macrophages treated in vitro with chemokine monocyte chemoattractant protein 1. Nitric Oxide 2001, 5:566-579

6. Biswas SK, Sodhi A: In vitro activation of murine peritoneal macrophages by monocyte chemoattractant protein-1: upregulation of $\mathrm{CD} 11 \mathrm{~b}$, production of proinflammatory cytokines, and the signal transduction pathway. J Interferon Cytokine Res 2002, 22:527-538

7. Tashiro K, Koyanagi I, Saitoh A, Shimizu A, Shike T, Ishiguro C, Koizumi M, Funabiki K, Horikoshi S, Shirato I, Tomino Y: Urinary levels of monocyte chemoattractant protein-1 (MCP-1) and interleukin8 (IL-8), and renal injuries in patients with type 2 diabetic nephropathy. J Clin Lab Anal 2002, 16:1-4

8. Nguyen D, Ping F, Mu W, Hill P, Atkins RC, Chadban SJ: Macrophage accumulation in human progressive diabetic nephropathy. Nephrology 2006, 11:226-231

9. Klessens CQ, Zandbergen M, Wolterbeek R, Bruijn JA, Rabelink TJ, Bajema IM, IJpelaar DHT: Macrophages in diabetic nephropathy in patients with type 2 diabetes. Nephrol Dial Transplant 2017, 32: $1322-1329$

10. Chow FY, Nikolic-Paterson DJ, Ozols E, Atkins RC, Rollin BJ, Tesch GH: Monocyte chemoattractant protein-1 promotes the development of diabetic renal injury in streptozotocin-treated mice. Kidney Int 2006, 69:73-80

11. Ninichuk V, Clauss S, Kulkarni O, Schmid H, Segerer S, Radomska E, Eulberg D, Buchner K, Selve N, Klussmann S, Anders HJ: Late onset of Ccl2 blockade with the Spiegelmer mNOX-E36-3'PEG prevents glomerulosclerosis and improves glomerular filtration rate in $\mathrm{db} / \mathrm{db}$ mice. Am J Pathol 2008, 172:628-637

12. Darisipudi MN, Kulkarni OP, Sayyed SG, Ryu M, Migliorini A, Sagrinati C, Parente E, Vater A, Eulberg D, Klussmann S, Romagnani P, Anders HJ: Dual blockade of the homeostatic chemokine CXCL12 and the proinflammatory chemokine CCL2 has additive protective effects on diabetic kidney disease. Am J Pathol 2011, 179: $116-124$

13. de Zeeuw D, Bekker P, Henkel E, Hasslacher C, Gouni-Berthold I, Mehling H, Potarca A, Tesar V, Heerspink HJ, Schall TJ; CCX140-B Diabetic Nephropathy Study Group: The effect of CCR2 inhibitor CCX140-B on residual albuminuria in patients with type 2 diabetes and nephropathy: a randomised trial. Lancet Diabetes Endocrinol 2015, 3:687-696

14. Menne J, Eulberg D, Beyer D, Baumann M, Saudek F, Valkusz Z, Wiecek A, Haller H; Emapticap Study Group: C-C motif-ligand 2 inhibition with emapticap pegol (NOX-E36) in type 2 diabetic patients with albuminuria. Nephrol Dial Transplant 2017, 32: 307-315

15. Boels MG, Avramut MC, Koudijs A, Dane MJ, Lee DH, van der Vlag J, Koster AJ, van Zonneveld AJ, van Faassen E, Grone HJ, van den Berg BM, Rabelink TJ: Atrasentan reduces albuminuria by restoring the glomerular endothelial glycocalyx barrier in diabetic nephropathy. Diabetes 2016, 65:2429-2439
16. Nieuwdorp M, Mooij HL, Kroon J, Atasever B, Spaan JA, Ince C, Holleman F, Diamant M, Heine RJ, Hoekstra JB, Kastelein JJ, Stroes ES, Vink H: Endothelial glycocalyx damage coincides with microalbuminuria in type 1 diabetes. Diabetes 2006, $55: 1127-1132$

17. van den Hoven MJ, Rops AL, Bakker MA, Aten J, Rutjes N, Roestenberg P, Goldschmeding R, Zcharia E, Vlodavsky I, van der Vlag J, Berden JH: Increased expression of heparanase in overt diabetic nephropathy. Kidney Int 2006, 70:2100-2108

18. Garsen M, Rops AL, Dijkman H, Willemsen B, van Kuppevelt TH, Russel FG, Rabelink TJ, Berden JH, Reinheckel T, van der Vlag J: Cathepsin $\mathrm{L}$ is crucial for the development of early experimental diabetic nephropathy. Kidney Int 2016, 90:1012-1022

19. Kalnins A, Thomas MN, Andrassy M, Muller S, Wagner A, Pratschke S, Rentsch M, Klussmann S, Kauke T, Angele MK, Bazhin AV, Fischereder M, Werner J, Guba M, Andrassy J: Spiegelmer inhibition of MCP-1/CCR2: potential as an adjunct immunosuppressive therapy in transplantation. Scand J Immunol 2015, 82: 102-109

20. Austyn JM, Gordon S: F4/80, a monoclonal antibody directed specifically against the mouse macrophage. Eur J Immunol 1981, 11 : 805-815

21. Ezekowitz RA, Gordon S: Alterations of surface properties by macrophage activation: expression of receptors for $\mathrm{Fc}$ and mannoseterminal glycoproteins and differentiation antigens. Contemp Top Immunobiol 1984, 13:33-56

22. Faas FG, Avramut MC, van den Berg BM, Mommaas AM, Koster AJ, Ravelli RB: Virtual nanoscopy: generation of ultra-large high resolution electron microscopy maps. J Cell Biol 2012, 198:457-469

23. Maecker HT, Frey T, Nomura LE, Trotter J: Selecting fluorochrome conjugates for maximum sensitivity. Cytometry A 2004, 62: $169-173$

24. Ehling J, Bartneck M, Wei X, Gremse F, Fech V, Mockel D, Baeck C, Hittatiya K, Eulberg D, Luedde T, Kiessling F, Trautwein C, Lammers T, Tacke F: CCL2-dependent infiltrating macrophages promote angiogenesis in progressive liver fibrosis. Gut 2014, 63: $1960-1971$

25. Abboud-Jarrous G, Atzmon R, Peretz T, Palermo C, Gadea BB, Joyce JA, Vlodavsky I: Cathepsin L is responsible for processing and activation of proheparanase through multiple cleavages of a linker segment. J Biol Chem 2008, 283:18167-18176

26. Shi C, Pamer EG: Monocyte recruitment during infection and inflammation. Nat Rev Immunol 2011, 11:762-774

27. Geissmann F, Jung S, Littman DR: Blood monocytes consist of two principal subsets with distinct migratory properties. Immunity 2003 , 19:71-82

28. Stenvinkel P, Ketteler M, Johnson RJ, Lindholm B, Pecoits-Filho R, Riella M, Heimburger O, Cederholm T, Girndt M: IL-10, IL-6, and TNF-alpha: central factors in the altered cytokine network of uremia-the good, the bad, and the ugly. Kidney Int 2005, 67: $1216-1233$

29. Goldberg R, Rubinstein AM, Gil N, Hermano E, Li JP, van der Vlag J, Atzmon R, Meirovitz A, Elkin M: Role of heparanase-driven inflammatory cascade in pathogenesis of diabetic nephropathy. Diabetes 2014, 63:4302-4313

30. Rabelink TJ, de Zeeuw D: The glycocalyx: linking albuminuria with renal and cardiovascular disease. Nat Rev Nephrol 2015, 11 : 667-676

31. Zetser A, Levy-Adam F, Kaplan V, Gingis-Velitski S, Bashenko Y, Schubert S, Flugelman MY, Vlodavsky I, Ilan N: Processing and activation of latent heparanase occurs in lysosomes. J Cell Sci 2004, $117: 2249-2258$

32. Wang F, Wang Y, Zhang D, Puthanveetil P, Johnson JD, Rodrigues B: Fatty acid-induced nuclear translocation of heparanase uncouples glucose metabolism in endothelial cells. Arterioscler Thromb Vasc Biol 2012, 32:406-414 
33. Simeonovic CJ, Ziolkowski AF, Wu Z, Choong FJ, Freeman C, Parish CR: Heparanase and autoimmune diabetes. Front Immunol 2013, 4:471

34. Rabelink TJ, van den Berg BM, Garsen M, Wang G, Elkin M, van der Vlag J: Heparanase: roles in cell survival, extracellular matrix remodelling and the development of kidney disease. Nat Rev Nephrol 2017, 13:201-212

35. Bogdani M, Johnson PY, Potter-Perigo S, Nagy N, Day AJ, Bollyky PL, Wight TN: Hyaluronan and hyaluronan binding proteins accumulate in both human type 1 diabetic islets and lymphoid tissues and associate with inflammatory cells in insulitis. Diabetes 2014, 63 . $2727-2743$

36. Garsen M, Benner M, Dijkman HB, van Kuppevelt TH, Li JP, Rabelink TJ, Vlodavsky I, Berden JH, Rops AL, Elkin M, van der Vlag J: Heparanase is essential for the development of acute experimental glomerulonephritis. Am J Pathol 2016, 186:805-815
37. Creasy BM, McCoy KL: Cytokines regulate cysteine cathepsins during TLR responses. Cell Immunol 2011, 267:56-66

38. Tarabra E, Giunti S, Barutta F, Salvidio G, Burt D, Deferrari G, Gambino R, Vergola D, Pinach S, Perin PC, Camussi G, Gruden G: Effect of the monocyte chemoattractant protein-1/CC chemokine receptor 2 system on nephrin expression in streptozotocin-treated mice and human cultured podocytes. Diabetes 2009, 58:2109-2118

39. Faul C, Donnelly M, Merscher-Gomez S, Chang YH, Franz S, Delfgaauw J, Chang JM, Choi HY, Campbell KN, Kim K, Reiser J, Mundel P: The actin cytoskeleton of kidney podocytes is a direct target of the antiproteinuric effect of cyclosporine A. Nat Med 2008, 14:931-938

40. Wada T, Furuichi K, Sakai N, Iwata Y, Yoshimoto K, Shimizu M, Takeda SI, Takasawa K, Yoshimura M, Kida H, Kobayashi KI, Mukaida N, Naito T, Matsushima K, Yokoyama H: Up-regulation of monocyte chemoattractant protein-1 in tubulointerstitial lesions of human diabetic nephropathy. Kidney Int 2000, 58:1492-1499 